\title{
Sciendo SHIP'S OPERATIONAL SPEED ON THE PLANNED OCEAN ROUTE IN REAL WEATHER CONDITIONS
}

DOI 10.2478/ntpe-2018-0020

\author{
prof. dr hab. inż. Tadeusz Szelangiewicz \\ dr hab. inż. Katarzyna Żelazny, prof. AM \\ Maritime University of Szczecin, Poland
}

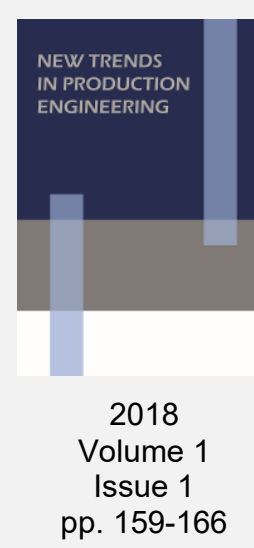

\begin{abstract}
While operating the ship, one of the most important tasks is forecasting the ocean route. For this purpose, the speed characteristics of the ship are used, which are used in specialized computer systems and presented in publications. However, published algorithms for speed (or decrease of speed) calculations of a ship in real weather conditions on given routes are very simplified and do not contain all the relevant parameters related to the ship's hull (affecting its resistance when sailing, eg on waves), its propulsion and weather conditions. The article presents its own, more detailed mathematical model of the speed of the ship, and the performed calculations of speed of the ship were compared with the algorithms available in the literature and with the records from the ship's log.
\end{abstract}

Keywords: ocean route, ship speed, weather parameters, ship propulsion

\section{INTRODUCTION}

During the operation of the transport ship, one of the most important tasks having a large impact on operating costs is forecasting the ocean shipping route for real weather parameters (Myung-II, 2013, Perera and Guedes, 2017, Journee and Meijers, 1980).

Forecasting of the shipping route is carried out according to various criteria (Prpic-Orsic et al., 2016, Wiśniewski, 2012), but regardless of what criterion is taken into account, it is very important to determine the speed at which the ship can move in weather conditions during navigation (Białostocki and Konovessis, 2016). The previous article presents a mathematical model for calculating the total resistance and speed of the ship in real weather conditions. This article presents the mathematical model of the ship propulsion and the results of calculations of the operating speed of a given ship under given weather conditions.

The obtained results were compared with approximate (simple) mathematical models and logbook entries made on operated ships.

\section{GENERAL MATHEMATICAL MODEL FOR CALCULATION OF THE SHIP'S OPERATIONAL SPEED}

During the voyage along the ocean route, in addition to the resistance from the water, the ship is affected by wind, wave, surface sea currents, causing additional resistance. Keeping of the ship at a given course with the help of a rudder blade with the oblique action of wind and waves creates additional resistance from the rudder. The operating speed $V$ with which the vessel can sail results from the balance between the total resistance $R_{T}$ and the thrust force $T$ of the propeller:

$$
T=\frac{R_{T}}{1-t}
$$

where:

$t$ is the suction coefficient (the value of the suction coefficient may depend on the speed of the vessel $t(V))$.

Torque is generated on the working propeller $Q$ :

$$
Q=K_{Q} \rho_{w} D_{p}^{5} n_{p}^{2}
$$


where:

$K_{Q} \quad$ - torque coefficient on the propeller,

$\rho_{w}-$ water density,

$D_{P} \quad$ - diameter of the propeller,

$n_{p} \quad-$ rotation speed of the propeller.

Between the moment $Q$ on the propeller and the power applied to the propeller $P_{D}$ is the following relationship:

$$
P_{D}=Q \cdot 2 \pi n_{p}
$$

between power $P_{D}$ and the power of the drive motor $N$ :

$$
N=\frac{P_{D}}{\eta_{G} \cdot \eta_{S} \cdot \eta_{R T}}
$$

where:

$\eta_{G}-$ gearbox efficiency, if used,

$\eta_{S} \quad$ - the efficiency of the shaft line,

$\eta_{R T}$ - rotational "efficiency" (rotational "efficiency" may vary depending on the speed of the ship $\left.\eta_{R T}(V)\right)$.

The article (Szelangiewicz and Żelazny, 2006) presents equations describing the total resistance of the ship during a voyage along the ocean route. Propeller thrust results from the speed of the ship and possible motions of the ship on the wave (mainly when the propeller emerges), and from the position of the equilibrium point between $R_{T}$ and $T$ in the field of operation of the propulsion engine.

\section{Working field and characteristics propulsion}

For the designed vessel, the engine power is selected so that the operating point of the drive system for the contractual speed on calm water is about $0.90 N_{n}$ (nominal power of the engine). In real weather conditions, when the ship is affected by wind and waves, and there is an additional resistance $\Delta R$ from weather conditions, the working point of the drive system will change its position in the field of operation of the propulsion engine. By controlling the fuel dose (and thus the engine and propeller rotational speed), the operating point can be located in the continuous work area (green field - Fig. 1) or in the work area limited by engine overload (yellow or red field - Fig. 1).

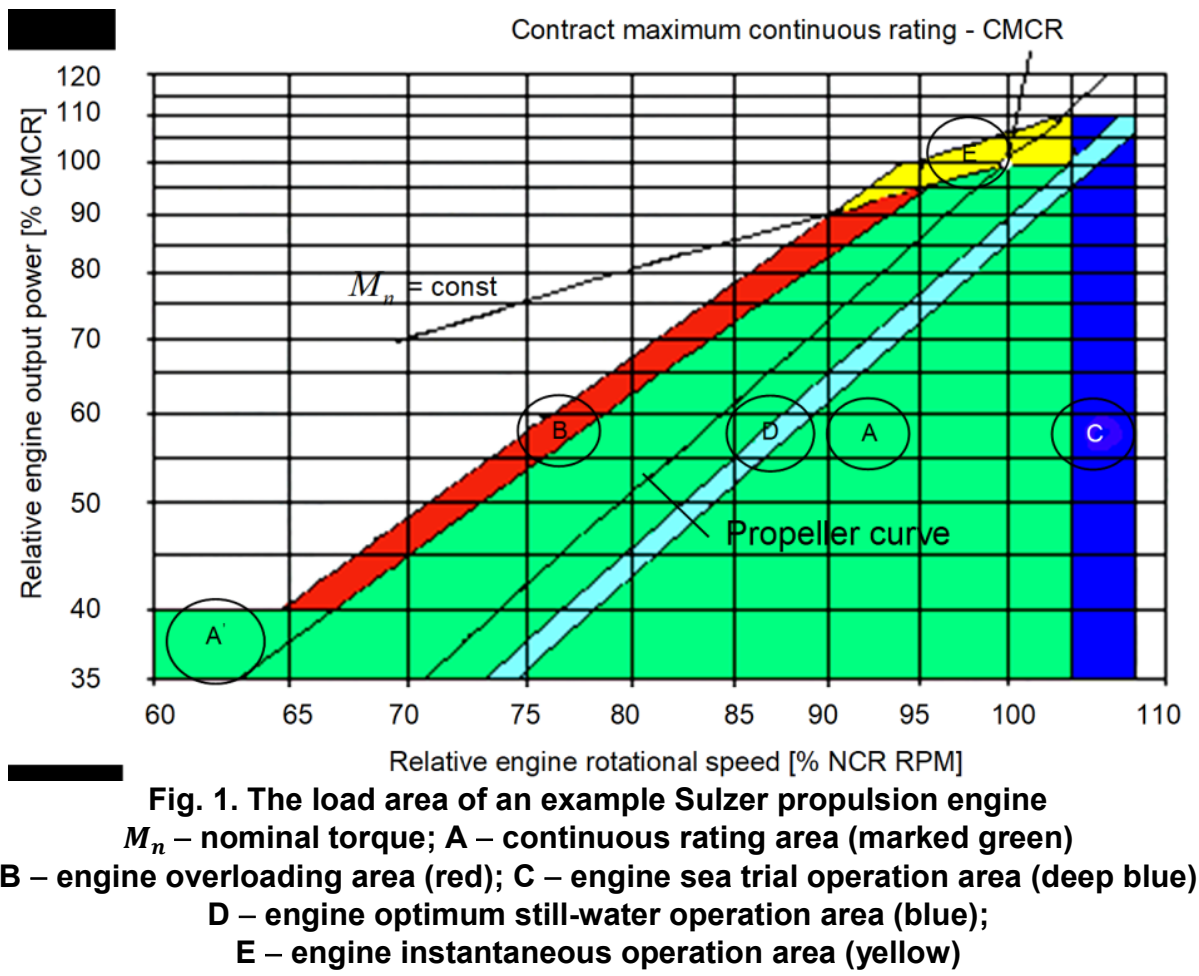


The particular areas are limited by the engine performance characteristic curve in the following from:

$$
N=k_{m} \cdot n^{m}
$$

where:

$N \quad$ - engine output power,

$k_{m}$ - coefficient for a given characteristic curve,

$n$ - engine rotational speed,

$m$ - exponent depending on a type of engine of a given producer.

The propulsion characteristics of the ship are power curves, thrust, efficiency and torque on the propeller, fuel consumption presented as a function of the rotational speed of the propeller (engine) and as a function of the ship's speed for various resistance characteristics resulting from wind, wave and sea currents.

Fig. 2 contains exemplary, calculated propulsion characteristics for a constant wind speed in an arbitrary direction in relation to the ship's direction of movement (in this case, the ship sail upwind - propulsive characteristics can be represented for any wind directions and/or wave). Such characteristics enable the correct choice of the operating point of the propulsion system in changing weather conditions or prediction of eg the maximum speed of the ship, which can be achieved with the deteriorating sea conditions.

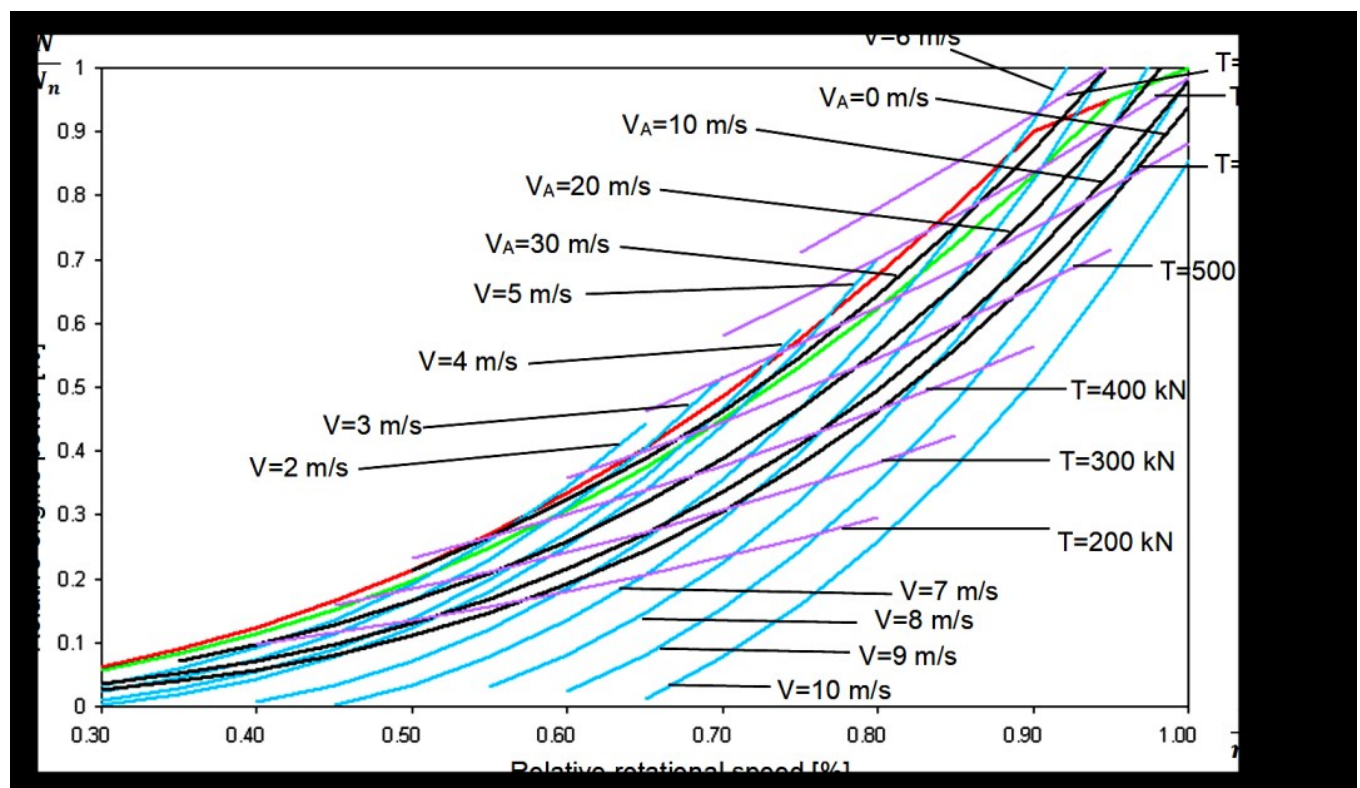

Fig. 2. Characteristics of the ship's constant speed (container ship: $L=140.14 \mathrm{~m}, B=22.3 \mathrm{~m}$, $d=8.25 \mathrm{~m}, \nabla=17290 \mathrm{~m}^{3}$ ), constant thrust $T$ propeller and constant wind speed $V_{A}$

Possibility of changing the operating point of the propulsion system (fixed pitch propeller) caused by the increase of additional resistance, in this case from the wind (the ship is sailing upwind), shown in Fig. 3. In this example, the vessel is in calm water in the starting position (point B) with $V_{B}$ speed and propeller speed $n_{B}$ and wind speed $V_{A}=0 \mathrm{~m} / \mathrm{s}$. Then an additional resistance arises from the up wind at the velocity $V_{A}=10 \mathrm{~m} / \mathrm{s}$ from the bow. The following paths are possible from the current work point (point $B$ ) to the new operating point (point $C$ ) of the propulsion system (Fig. 3):

a) while maintaining the constant speed $n_{B}$, the fuel dose increases (the engine power increases) until reaching the $C$ point on the $V_{A}$ characteristic, the speed of the vessel drops to the value $V_{C}$;

b) while maintaining the constant speed of the $V_{B}$ vessel, the fuel dose increases (engine power increases and the rotational speed is increased to $n_{C}$ ) until reaching the $C$ point (the constant speed of the vessel can be maintained up to the limit curve for a given engine); 
c) maintaining the constant engine power, the point $C$ is reached, the vessel speed to $V_{C}$ and engine speed to the vessel are reduced $n_{C}$;

d) by maintaining a constant unit fuel consumption until reaching point $\mathrm{C}$, the speed of the vessel and the engine speed are reduced.

The aforementioned 4 possibilities to achieve a new work point of the ship's propulsion system - in this case - the wind speeds can be used with different criteria, eg: constant speed of the ship, maximum possible speed of the ship, minimum fuel consumption or constant or maximal efficiency propeller.

a) constant rotational speed

b) constant speed of the ship

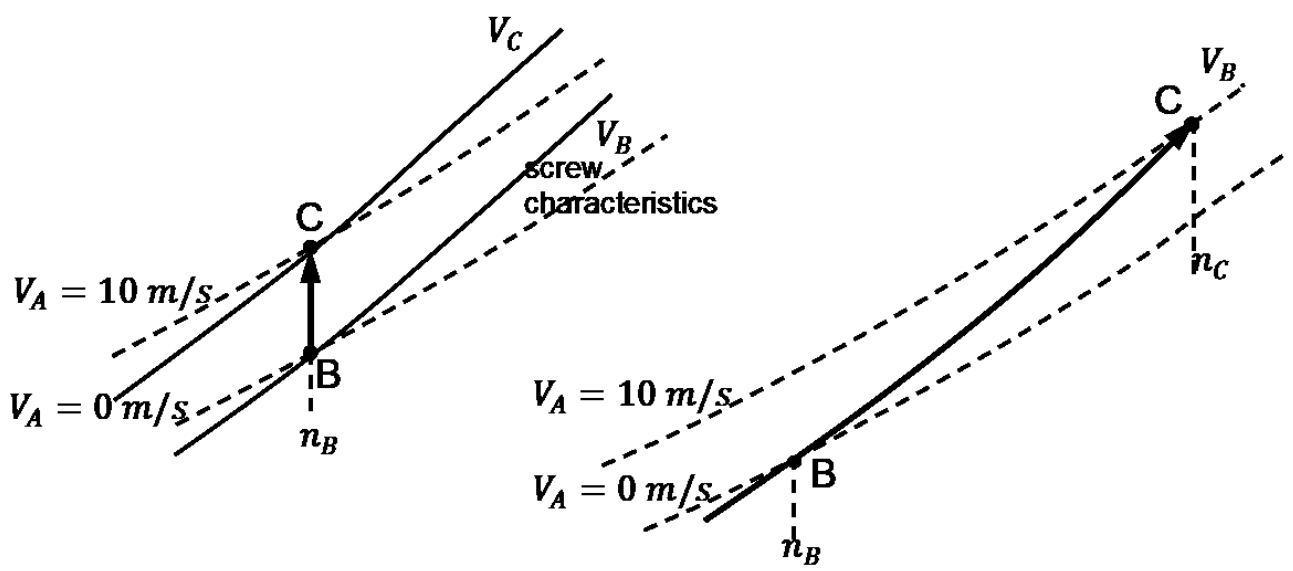

c) constant engine power

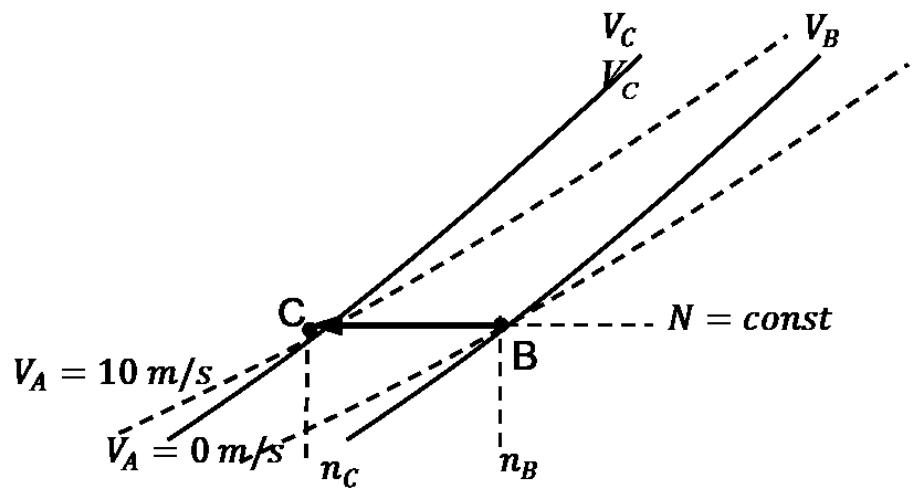

d) constant unit fuel consumption

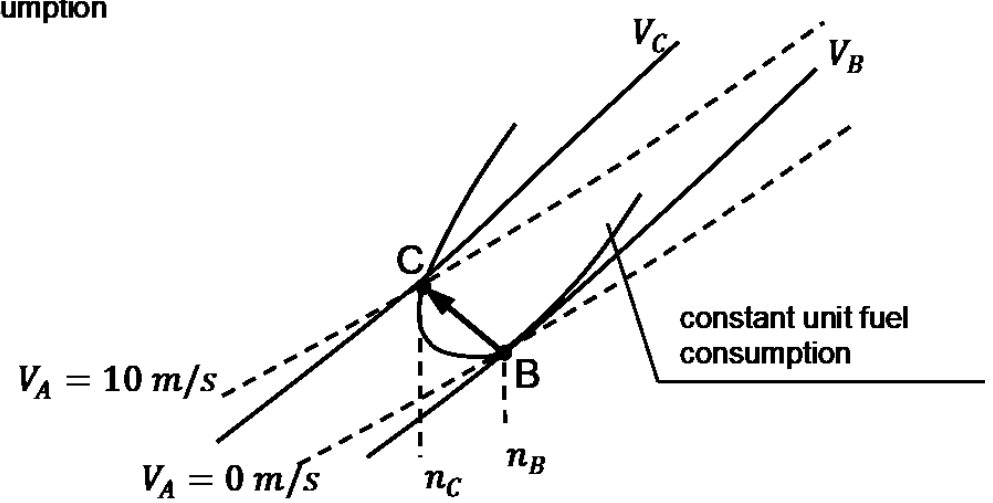

Fig. 3. Examples of changing the operating point of the propulsion system as a result of an increase in additional resistance due to weather conditions

The speed of the ship for the forecasted ocean-going route, apart from the additional resistance from actual weather conditions, is also affected by the selected criterion of the propulsion engine motor (position of the working point) shown in Fig. 3. In commonly used, simplified ship speed prediction algorithms, such criteria are not considered. 


\section{RESULTS OF CALCULATION OF SHIP OPERATING SPEED IN REAL WEATHER CONDITIONS}

Calculations of the ship's operating speed made according to our own algorithm were compared with calculations made according to available algorithms presented in the literature or observations made on similar vessels.

- For forecasting ocean routes, the most suitable computer systems are: SPOS (SPOS Program, 2009, Wiśniewski, 2012), Bon Voyage (Bon Voyage System, 2016). In both systems, simple algorithms are used to calculate the speed of the ship (or decrease speed) in real weather conditions, in which several parameters of the vessel are used (length between perpendiculars $L_{P P}$, breadth $B$, draft $d$, nominal power $N C R$ and nominal speed $R P M$ of the engine propulsion, vessel design speed $V$ ). Such a number of parameters as well as the lack of an algorithm do not allow for calculation of the operating speed of the ship in real weather conditions.

- The publication (Schneekluth and Bertram, 1998) presents a simple algorithm for calculating decrease speed of the ship in real weather conditions:

$$
\frac{\Delta V}{V} \cdot 100 \%=c_{\mu} \cdot c_{\text {ship }} \text {, }
$$

for the container ship:

$$
\begin{array}{ll}
r c_{\text {ship }}=0.7 B N+B N^{6,5} /\left(22 \cdot \nabla^{2 / 3}\right), \\
c_{\mu}=1.0 & \text { for } \mu=0^{\circ} \div 30^{\circ} \\
c_{\mu}=1.7-0,03(B N-4)^{2} & \text { for } \mu=30^{\circ} \div 60^{\circ} \\
c_{\mu}=0.9-0,06(B N-6)^{2} & \text { for } \mu=60^{\circ} \div 150^{\circ} \\
c_{\mu}=0.4-0,03(B N-8)^{2} & \text { for } \mu=150^{\circ} \div 180^{\circ}
\end{array}
$$

where:

$V \quad$ - speed of the ship on calm water,

$B N$ - Beaufort number,

$\nabla \quad$ - displacement of the container ship [ $\left.\mathrm{m}^{3}\right]$,

$\mu \quad-$ wind direction and wave direction relative to the ship.

The above algorithm:

\begin{tabular}{|c|c|c|c|c|}
\hline \multirow{3}{*}{\multicolumn{2}{|c|}{$\begin{array}{c}\Delta V \text { acc (Schneekluth } \\
\text { and Bertram, 1998) } \\
B N=7 \\
V_{A}=13.9-17.1 \mathrm{~m} / \mathrm{s} \\
H_{S}=3.5-6.0 \mathrm{~m} \\
T_{1}=7.4-9.8 \mathrm{~s}\end{array}$}} & \multirow{2}{*}{\multicolumn{3}{|c|}{$\frac{\Delta V \text { according to own algorithm }}{B N=7}$}} \\
\hline & & & & \\
\hline & & & $\begin{array}{c}V_{A}=13.9 \mathrm{~m} / \mathrm{s} \\
H_{S}=3.5 \mathrm{~m} \\
T_{1}=7.4 \mathrm{~s}\end{array}$ & $\begin{array}{c}V_{A}=17.1 \mathrm{~m} / \mathrm{s} \\
H_{S}=6.0 \mathrm{~m} \\
T_{1}=9.8 \mathrm{~s}\end{array}$ \\
\hline$\mu=0^{\circ}-30^{\circ}$ & $2.42 \mathrm{~m} / \mathrm{s},(26.1 \%)$ & $\mu=0^{\circ}$ & $0.56 \mathrm{~m} / \mathrm{s},(6.1 \%)$ & $3.28 \mathrm{~m} / \mathrm{s},(35.3 \%)$ \\
\hline$\mu=30^{\circ}-60^{\circ}$ & $3.46 \mathrm{~m} / \mathrm{s},(37.3 \%)$ & $\mu=30^{\circ}$ & $0.82 \mathrm{~m} / \mathrm{s},(8.8 \%)$ & $6.15 \mathrm{~m} / \mathrm{s},(66.1 \%)$ \\
\hline$\mu=60^{\circ}-150^{\circ}$ & $2.23 \mathrm{~m} / \mathrm{s},(21.9 \%)$ & $\mu=60^{\circ}$ & $1.27 \mathrm{~m} / \mathrm{s},(13.6 \%)$ & $6.47 \mathrm{~m} / \mathrm{s},(68.9 \%)$ \\
\hline$\mu=150^{\circ}-180^{\circ}$ & $0.89 \mathrm{~m} / \mathrm{s},(9.6 \%)$ & $\mu=150^{\circ}$ & $0.09 \mathrm{~m} / \mathrm{s},(1.0 \%)$ & $0.14 \mathrm{~m} / \mathrm{s},(1.5 \%)$ \\
\hline & & $\mu=180^{\circ}$ & $0.05 \mathrm{~m} / \mathrm{s},(0.5 \%)$ & $0.09 \mathrm{~m} / \mathrm{s},(1.0 \%)$ \\
\hline
\end{tabular}

- it contains only the displacement $\nabla$ of the container ship,

- instead of a specific value of wind speed and wave height, it contains only the Beaufort number $B N$,

- the directions of wind and wave in the presented algorithm are exactly the same in relation to the ship (in fact, the directions of wind and waves can be different).

Table 1 presents the results of calculations of the ship's speed decrease on the basis of the (Schneekluth and Bertram, 1998) and own algorithm.

Table 1.

Calculation example 1 for a container $\operatorname{ship}\left(L=140.14 \mathrm{~m}, B=22.3 \mathrm{~m}, d=8.25 \mathrm{~m}, \nabla=17290 \mathrm{~m}^{3}\right)$

The speed decrease calculations in Table 1 show that the use of only the Beaufort number in the algorithm (Schneekluth and Bertram, 1998) does not allow precise determination of the speed of the ship, since the Beaufort number refers to a specific range of wind speed and wave height. 
The publication (Rudiajew, 1968) presents a speed decrease algorithm, which takes into account a larger number of parameters characterizing of the ship:

$$
\begin{gathered}
\Delta V=\Delta V_{f}+\Delta V_{w}, \\
\Delta V_{f}=\left[A^{2} C^{2}+2 A \cdot C\left(0.5 c \cdot \cos q_{f}+V_{0}\right)\right]^{1 / 2}-A \cdot C, \\
A=\frac{10^{-3} \delta L B g^{3} \rho^{2} h^{2}}{2 \pi D} \\
C=1-\exp \left(-\frac{4 \pi T_{S}}{\lambda}\right) \\
\Delta V_{w}=V_{0}-\left[\frac{V_{0}^{2}\left(1+k_{q}\right)-k_{q} W^{2}+2 A \cdot C\left(0.5 c \cdot \cos q_{f}+V_{0}\right)}{1+k_{q}}\right]^{1 / 2}+\frac{k_{q} W}{1+k_{q}} \cos q_{w},
\end{gathered}
$$

where:

$k_{q}=\frac{c_{q} S}{800 \varepsilon \Omega}-$ wind rate of the ship,

$L \quad$ - the length of the ship [m],

$B$ - breadth of the ship [m],

$T_{S} \quad-$ draught of the ship [m],

$\delta$ - block coefficient,

$D$ - displacement of the ship [t],

$S$ - surface of the above-water part of the ship, created by dropping into the diametral plane $\left[\mathrm{m}^{2}\right]$,

$\Omega \quad$ - surface of the wetted $\left[\mathrm{m}^{2}\right]$,

$V_{0} \quad$ - ship's speed on calm water $[\mathrm{m} / \mathrm{s}]$,

$C_{q}$ - coefficient of air resistance corresponding to the specified exchange rate of wind operation per vessel,

$\varepsilon-$ coefficient of water resistance,

$h$ - the average wave height in the wave spectrum [m],

$\lambda$ - wavelength corresponding to the adopted wave height [m],

$c$ - phase speed of the wave $[\mathrm{m} / \mathrm{s}]$,

$q_{f} \quad$ - wave angle $\left[^{\circ}\right]$,

$q_{w}$ - the angle of the wind $\left[^{\circ}\right]$,

$W$ - real wind speed $[\mathrm{m} / \mathrm{s}]$,

$g \quad-$ acceleration of the earth $\left[\mathrm{m} / \mathrm{s}^{2}\right]$,

$\rho \quad-$ water density $\left[\mathrm{t} / \mathrm{m}^{3}\right]$.

\begin{tabular}{|c|c|c|c|c|}
\hline \multicolumn{5}{|c|}{$B N=7$} \\
\hline \multirow{2}{*}{$\begin{array}{c}\text { wave } \\
\text { and wind } \\
\text { direction }\end{array}$} & \multicolumn{2}{|c|}{$\begin{array}{c}V_{A}=13.9 \mathrm{~m} / \mathrm{s}, H_{S}=3.5 \mathrm{~m} \\
T_{1}=7.4 \mathrm{~s}\end{array}$} & \multicolumn{2}{|c|}{$\begin{array}{c}V_{A}=17.1 \mathrm{~m} / \mathrm{s}, H_{S}=6.0 \mathrm{~m} \\
T_{1}=9.8 \mathrm{~s}\end{array}$} \\
\hline & $\begin{array}{c}\Delta V \text { acc } \\
\text { (Rudiajew, 1968) }\end{array}$ & $\begin{array}{l}\Delta V \text { according } \\
\text { to own algorithm }\end{array}$ & $\begin{array}{c}\Delta V \text { acc } \\
\text { (Rudiajew, 1968) }\end{array}$ & $\begin{array}{l}\Delta V \text { according } \\
\text { to own algorithm }\end{array}$ \\
\hline$\mu=0^{\circ}$ & $1.59 \mathrm{~m} / \mathrm{s},(17.0 \%)$ & $0.56 \mathrm{~m} / \mathrm{s},(6.1 \%)$ & $3.45 \mathrm{~m} / \mathrm{s},(37.1 \%)$ & $3.28 \mathrm{~m} / \mathrm{s},(35.3 \%)$ \\
\hline$\mu=30^{\circ}$ & $1.69 \mathrm{~m} / \mathrm{s},(18.1 \%)$ & $0.82 \mathrm{~m} / \mathrm{s},(8.8 \%)$ & $3.57 \mathrm{~m} / \mathrm{s},(38.4 \%)$ & $6.15 \mathrm{~m} / \mathrm{s},(66.1 \%)$ \\
\hline$\mu=60^{\circ}$ & $1.31 \mathrm{~m} / \mathrm{s},(14.1 \%)$ & $1.27 \mathrm{~m} / \mathrm{s},(13.6 \%)$ & $2.94 \mathrm{~m} / \mathrm{s},(31.5 \%)$ & $6.47 \mathrm{~m} / \mathrm{s},(69.5 \%)$ \\
\hline$\mu=150^{\circ}$ & $0.89 \mathrm{~m} / \mathrm{s},(9.6 \%)$ & $0.09 \mathrm{~m} / \mathrm{s},(1.0 \%)$ & $1.61 \mathrm{~m} / \mathrm{s},(17.3 \%)$ & $0.14 \mathrm{~m} / \mathrm{s},(1.5 \%)$ \\
\hline$\mu=180^{\circ}$ & $0.89 \mathrm{~m} / \mathrm{s},(9.5 \%)$ & $0.05 \mathrm{~m} / \mathrm{s},(0.5 \%)$ & $1.52 \mathrm{~m} / \mathrm{s},(16.3 \%)$ & $0.09 \mathrm{~m} / \mathrm{s},(1.0 \%)$ \\
\hline
\end{tabular}

Table 2 presents the results of calculations of the speed decrease of the ship based on the algorithm (Rudiajew, 1968) and own.

Table 2.

Calculation example 2 for a container $\operatorname{ship}\left(L=140.14 \mathrm{~m}, B=22.3 \mathrm{~m}, d=8.25 \mathrm{~m}, \nabla=17290 \mathrm{~m}^{3}\right)$

Comparison of own calculations of speed decrease with observations made on the ship. The results of calculations are shown in Figure 4.

To assess the obtained results of the calculations, measurements and observations made on a similar "Diana" type ship were used (Szelangiewicz et al., 2014). The results of observations 
from the ship "Diana" differ from the calculations not only because it is not exactly the same ship, but also because:

- observations made on the ship "Diana" are averaged from 4 hours;

- wind and wave parameters are determined in a very approximate way;

$\circ$ the speed decrease takes into account the deliberate reduction resulting from excessive motions;

- there is no information about the rotational speed of the propulsion engine, the fuel dose or where the operating point on the engine load field was located.

\section{Bulk carrier $L_{P P}=185.0 \mathrm{~m}$}

Own calculations

a)

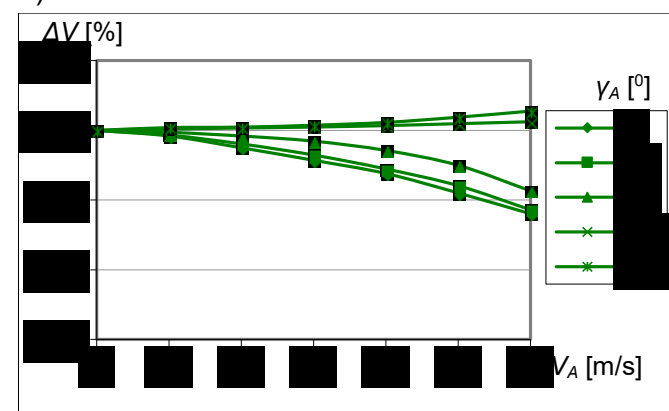

b)

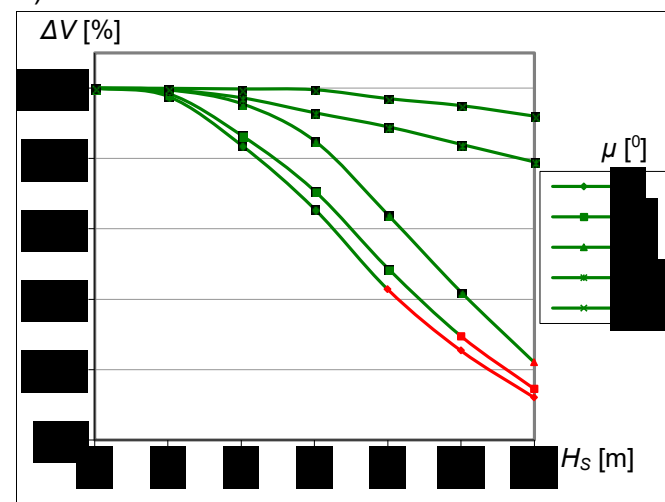

c)

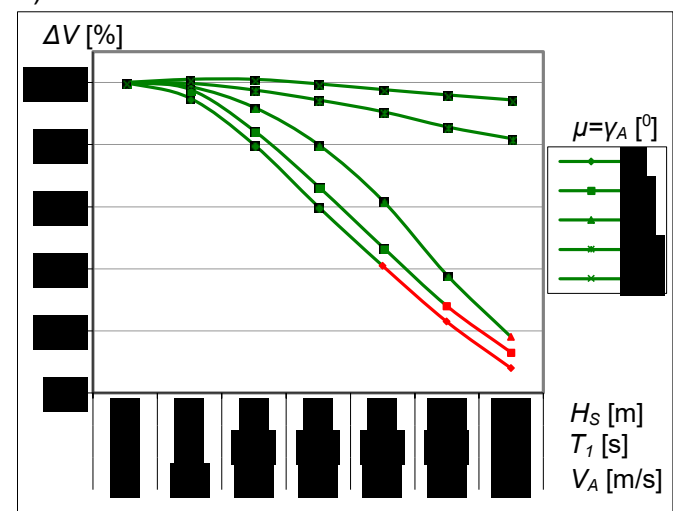

Bulk carrier series "Diana"

$L_{P P}=186.0 / 177.0 \mathrm{~m}$

Observations on the ship
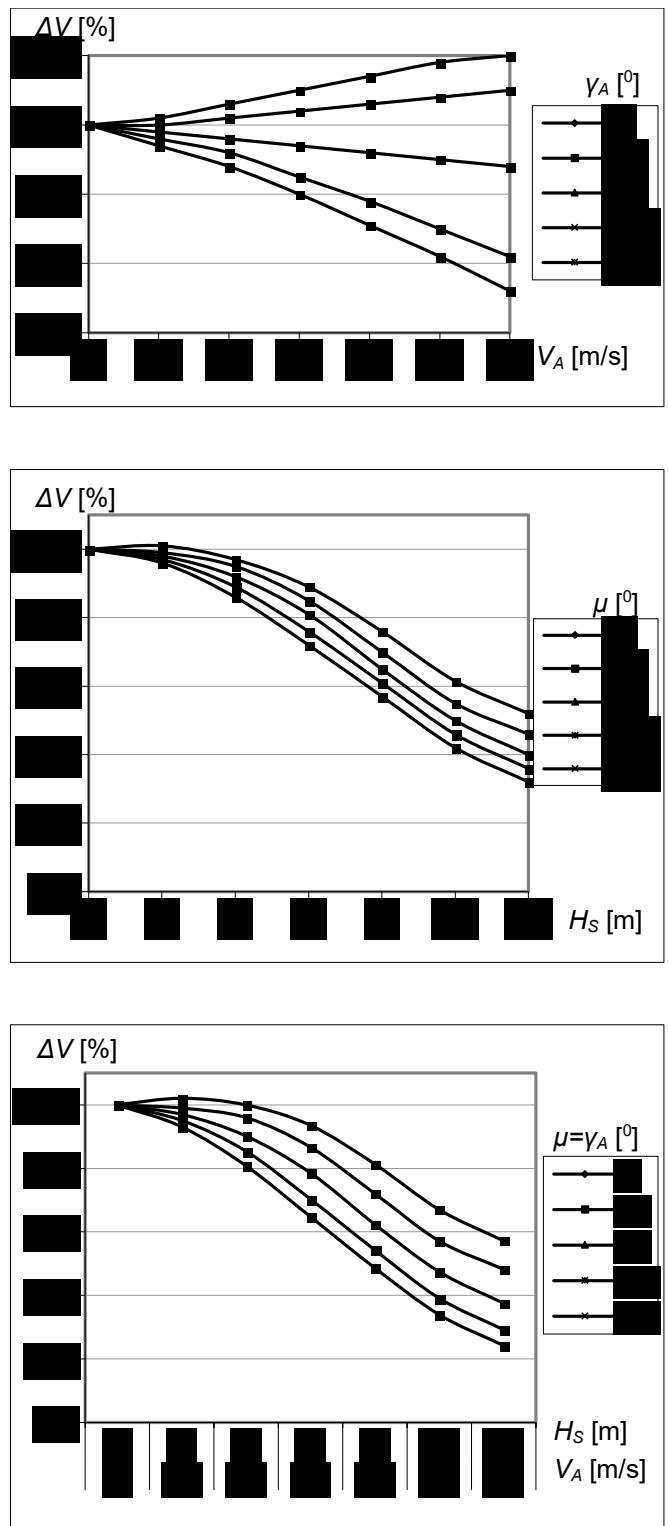

Fig. 4. Speed decrease with different parameters as well as wave and wind directions for the ship's course $\psi=0^{\circ}$

(green color - continuous operation without overload; red color - motor overload,

Fig. 1) a) wind influence, b) the influence of waving, c) wind and wave effects

\section{CONCLUSIONS}

1. Presented own mathematical model of calculating the operating speed of the ship in real weather conditions includes: 
- full information about the shape of the hull and superstructures (many geometrical parameters are used in the model),

- coefficients of aerodynamic and hydrodynamic resistance include any wind, current and wave directions as well as the drift angle of the vessel,

- additional resistance to layed the rudder,

- full hydrodynamic characteristics of the layed propeller,

- full working field of the propulsion engine and the possibility of an optimal selection of the working point depending on the adopted criteria and changing weather parameters.

2. The calculation algorithms of speed (or speed decrease) presented in the literature are very simplified and contain only a small number of parameters characterizing the ship and its propulsion.

3. In the algorithms used, there is no additional resistance from the layed rudder in case the wind and wave act obliquely in relation to the ship.

4. In the algorithms used there are no criteria for the operation of the propulsion engine and therefore there is no possibility to optimize the operation of the propulsion system in changing weather conditions.

5. The calculation of the ship's speed decrease made using the own algorithm is consistent with the measurements made on a similar ship (Figure 4).

\section{REFERENCES}

Białostocki, N. and Konovessis, D. (2016). On the estimation of ship fuel consumption and speed curve: A statistical approach. Journal of Ocean Engineering and Science, 7(2), pp. 157-166.

Bon Voyage System (BVS) voyage optimization software. (2016). Applied Weather Technologies (AWT), Kifer Court. Sunnyvale CA 94086. V. 7.1.

Journee, J.M.J. and Meijers, J.H.C. (1980). Ship routeing for optimum performance. Transaction IME, pp.12-21.

Myung-II, R. (2013). Determination of an economical shipping route considering the effects of sea state for lower fuel consumption. International Journal of Naval Architecture and Ocean Engineering. 5(2). pp. 246-262.

Perera, L.P. and Guedes Soares, C. (2017). Weather Routing and Safe Ship Handling in the Future of Shipping. Ocean Engineering. 130. pp. 684-695.

Program SPOS Fleet Management. (2009). Meteo Consult BV, The Netherlands, V. 7.0.0.1.

Prpic-Orsic, J., Faltinsen, O. M. and Parunov, J. (2016). Influence of operability criteria limiting values on ship speed. BRODOGRADNJA, 67(3). pp. 37-58.

Rudiajew, F.J. (1968). Eniergieticzeskij mietod rasczota potier skorosti choda sudow na nieriegularnom wolnienii. Leningrad: Sudowożdienije.

Schneekluth, H. and Bertram, V. (1998). Ship Design for Efficiency and Economy. Oxford: Butterworth-Heinemann.

Szelangiewicz, T. and Żelazny, K. (2006). Calculation of the Mean Long-Term Service Speed of Transport Ship, Part I: Resistance of Ship Sailing on Regular Shipping Route in Real Weather Conditions. Polisch Maritime Research, 4(50), pp. 23-31.

Szelangiewicz, T., Wiśniewski, B. and Żelazny, K. (2014). The influence of wind, wave and loading condition on total resistance and speed of the vessel. Polish Maritime Research. 3(83). pp. 61-67.

Wisniewski, B. (2012). Ship's ocean route programing. Scientific Journals of the Maritime University of Szczecin - Zeszyty Naukowe Akademii Morskiej w Szczecinie, 29(101), pp. 164-173.

Wisniewski, B. (2012). The speed charakteristics adaptation of Polish Streamship Company's dry bulk vessels to SPOS. Scientific Journals of the Maritime University of Szczecin Zeszyty Naukowe Akademii Morskiej w Szczecinie, 30(102), pp. 143-149. 